\title{
Hypoxia reduces testosterone synthesis in mouse Leydig cells by inhibiting NRF1 -activated StAR expression
}

\author{
Xueting Wang ${ }^{1, *}$, Longlu Pan ${ }^{2, *}$, Zhiran Zou ${ }^{1}$, Dan Wang ${ }^{1}$, Yapeng Lu ${ }^{1}$, Zhangji Dong ${ }^{3}$, Li \\ Zhu $^{1,4}$ \\ ${ }^{1}$ Department of Biochemistry, Institute for Nautical Medicine, Nantong University, China \\ ${ }^{2}$ Department of Rehabilitation of the Six People's Hospital of Nantong, Jiangsu, China \\ ${ }^{3}$ Co-Innovation Center of Neuroregeneration, Jiangsu Key Laboratory of Neuroregeneration, Nantong University, Nantong, China \\ ${ }^{4}$ Key Laboratory of Neuroregeneration of Jiangsu and Ministry of Education, Co-Innovation Center of Neuroregeneration, \\ Nantong University, China \\ *These authors contributed equally to this work
}

Correspondence to: Li Zhu, email: zhulili65@126.com

Keywords: NRF1, StAR, testosterone synthesis, hypoxia, Leydig cells

Received: December 01, $2016 \quad$ Accepted: January 11, 2017

Published: January 27, 2017

\section{ABSTRACT}

Male fertility disorders play a key role in half of all infertility cases. Reduction in testosterone induced by hypoxia might cause diseases in reproductive system and other organs. Hypoxic exposure caused a significant decrease of NRF1. Software analysis reported that the promoter region of steroidogenic acute regulatory protein (StAR) contained NRF1 binding sites, indicating NRF1 promoted testicular steroidogenesis. The purpose of this study is to determine NRF1 is involved in testosterone synthesis; and under hypoxia, the decrease of testosterone synthesis is caused by lower expression of NRF1. We designed both in vivo and in vitro experiments. Under hypoxia, the expressions of NRF1 in Leydig cells and testosterone level were significantly decreased both in vivo and in vitro. Overexpression and interference NRF1 could induced StAR and testosterone increased and decreased respectively. ChIP results confirmed the binding of NRF1 to StAR promoter region. In conclusion, decline of NRF1 expression downregulated the level of StAR, which ultimately resulted in a reduction in testosterone synthesis.

\section{INTRODUCTION}

In recent years, the growing number of male infertility aroused broad attention. Kamali et al. reported that out of 2492 infertile cases from 1993 to 2001 , nearly $50.5 \%$ were related to male infertility, with only $11.6 \%$ were related to couple infertility [1]. Based on statistics released by the WHO, the prevalence of infertility is $10-15 \%$, among which $35-40 \%$ of cases are related to male infertility disorders. Thus, it can be concluded that male fertility disorders play a key role in half of all infertility cases.

Among several physiological effects, studies suggested that hypoxia reduces fertility in humans. It was demonstrated that people exposed to $7821 \mathrm{~m}$ above the sea level presented sperm counts decrease and an increase in the number of dysmorphic spermatozoa [2]. Histological examination of rat testes after hypoxic exposure has shown the changes in testicular morphology and loss of spermatogenic cells $[3,4]$. Until now the mechanism of hypoxia induced infertility was still unclear. One study performed by Madrid et al. in 2013 showed that high-altitude hypoxia induced plasmatic and testicular testosterone decreases since the 5th day [5]. As we know, testosterone plays an important role in the male reproductive system, by promoting sperm maturation and maintaining male secondary sex characteristics. Testosterone also promotes reproductive organ function, muscle protein synthesis, bone growth, calcium and phosphorus deposition and red blood cell formation. Studies have indicated that androgen deficiency led to not only male sexual dysfunction, erectile dysfunction, decreased reproductive capacity, but also cardiovascular disease [6], diabetes [7], osteoporosis and other diseases [8]. Thus, hypoxia-induced testosterone decrease might be one reason of male infertility. 
Nuclear respiratory factor 1 (NRF1) is a transcription factor that regulates expression of a spectrum of genes required for mitochondrial respiratory function. It was reported that treatment with hypoxia mimetics $\mathrm{CoCl}_{2}$ or incubation with $2 \% \mathrm{O}_{2}$ in 3T3-L1 adipocyte cells reduced NRF1 expression [9]. Interestingly, as a physiological dependence of mitochondrial gene, NRF1 mRNA level is low in many tissues but much higher in testis and lung [10]. Pilot experiments also showed a decrease trend of NRF1 expression in testis. We suppose that NRF1 decrease was a possible cause of the testosterone reduction.

Testicular Leydig cells are the main androgenproducing cells in mammals. $95 \%$ testosterone of a man is released by Leydig cells, which are found adjacent to the seminiferous tubules in the testis. In physiological condition, Leydig cell steroidogenesis is modulated by $\mathrm{LH} / \mathrm{hCG}$, which stimulates cAMP-PKA signaling pathway, leading to the transferation of cholesterol from the cytoplasm to the mitochondria. Then cholesterol is converted to pregnenolone and released into cytoplasm following by the synthesis of testosterone through

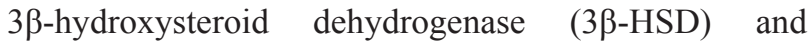
$17 \beta$-hydroxysteroid dehydrogenase (17 $\beta$-HSD) [11]. The transferation of cholesterol mediated by steroidogenic acute regulatory protein (StAR) is a rate-limiting step of testosterone synthesis, and StAR is the rate limiting protein of this process $[12,13]$. Software analysis prompted the promoter region of StAR contained a NRF1 binding region, or an antioxidant response elements (ARE), indicating NRF1 promotes testicular steroidogenesis.

In this study, we describe that NRF1 is involved in testosterone synthesis; and under hypoxia, lower expression of NRF1 reduces StAR expression, leading to the decrease of testosterone synthesis. These findings provide a molecular mechanism for NRF1-mediated induction of testosterone production in testicular Leydig cells under hypoxia.

\section{RESULTS}

\section{Distributions of NRF1 in different organs after hypoxia treatment}

To determine the effects of hypoxia on male mice, we first examined the distribution of NRF1 in different organs after hypoxia treatment. Organs including heart, liver, brain, lung and testis were collected to test the distributions of NRF1. We used Real-time PCR and Western Blot to detect the mRNA level and the protein level. As shown, the expression level of NRF1 in the heart (Figures 1A and 2A), liver (Figures 1B and 2B) and in the brain (Figure 1C) increased. On the contrast, the levels in the lung (Figures 1D and 2D) and the protein level in the brain (Figure 2C) significantly decreased. Interestingly, the decreased NRF1 level in testes were related with time (Figures 1E and 2E).

\section{Changes in NRF1 level and testosterone synthesis of Leydig cells under hypoxia condition}

Testicular tissue is mainly composed of three cell types, Sertoli, Leydig, and spermatogenic cells. We measured the expression levels of NRF1 in different cell types by immunofluorescence technique. Positive 33-HSD staining results confirmed Leydig cells, which also showed a much higher NRF1 level (Supplementary Figure 1). We were interested in the change of NRF1 level of Leydig cells after hypoxia treatments. So we also utilized the immunofluorescence technique for staining $3 \beta$-HSD (red) and NRF1 (green) of testicular tissue of mice treated with hypoxia. NRF1 was expressed in cytoplasm and NRF1 significantly decrease after hypoxia treatments (Figure 3A).

The main function of Leydig cells is the generation of testosterone. $95 \%$ of the testosterone is synthesized here. So the content of serum testosterone reflects the ability of Leydig cells to product testosterone. To measure the serum testosterone concentration, we collected mice serum and took the ELISA method. Results showed that the concentration of serum testosterone was decreased under hypoxia condition (Figure 3B).

To confirm the hypoxia effects of the NRF1 level and testosterone synthesis on Leydig cells, we isolated primary Leydig cells, which were treated with hypoxia $\left(1 \% \mathrm{O}_{2}\right.$ concentration). The purity of the cultured Leydig interstitial cells (Leydig cells) was higher than $98 \%$ by immunofluorescence (Supplementary Figure 2). Leydig cells were kept under hypoxia condition for $0,12,24$, 48 hours. NRF1 level was detected by real time-PCR, Western blot and ICC. Testosterone concentration was detected by Elisa. Results showed that the concentrations of serum testosterone were decreased under hypoxia condition and the NRF1 levels were decreased at both the mRNA and the protein level after hypoxia treatment (Figure 4A). Besides, the immunofluorescence results also suggested NRF1 showed obvious nuclear translocation after hypoxia treatment while the total expression decreased (Figure 4B). The testosterone of Leydig cells in the culture medium was detected by ELISA. The concentrations of testosterone were decreased under hypoxia condition (Figure 4C), which showed similar trend to the NRF1 changes. All results were consistent with the results of the in vivo experiments.

\section{NRF1 regulating the testosterone synthesis under normoxia and hypoxia conditions}

Both NRF1 and the testosterone were decreased in both testis and cultured Leydig cells. The trend of testosterone was consistent with the change of NRF1. Therefore, we hypothesized that NRF1 might be related to the synthesis of testosterone. Transfection with NRF1 small interfering RNAs and NRF1 overexpression plasmid was followed by normoxia or hypoxia treatment. The 
testosterone in the medium was detected by ELISA. As evident from Figure 5A, the siRNA-NRF1 brought about $40 \%$ decrease in NRF1 protein under normoxia and $85 \%$ decrease under hypoxia. Interestingly, siRNANRF1 transfected cells showed a significant decrease of testosterone levels under both normoxia and hypoxia as shown in Figure 5B and 5C. As evident from Figure 5E, 5F and $5 \mathrm{G}$, overexpression of the NRF1 significantly increased the testosterone levels under both normoxia and hypoxia.

\section{NRF1 promoting StAR expression resulting in the relative changes of testosterone synthesis}

Previous studies showed that NRF1 regulated gene transcription [14]. Therefore, we next determined whether NRF1 regulated the expression of genes involved in the pathway of testosterone synthesis. The potential binding sites of NRF1 to the regulatory region of StAR were found by Matlnspector software analysis. StAR is the rate-limiting step in the production of steroid hormones, which mediates cholesterol transfer into the mitochondria. As evidence from Figure 5D, StAR showed a significant decrease (50\% under normoxia and 60\% under hypoxia),
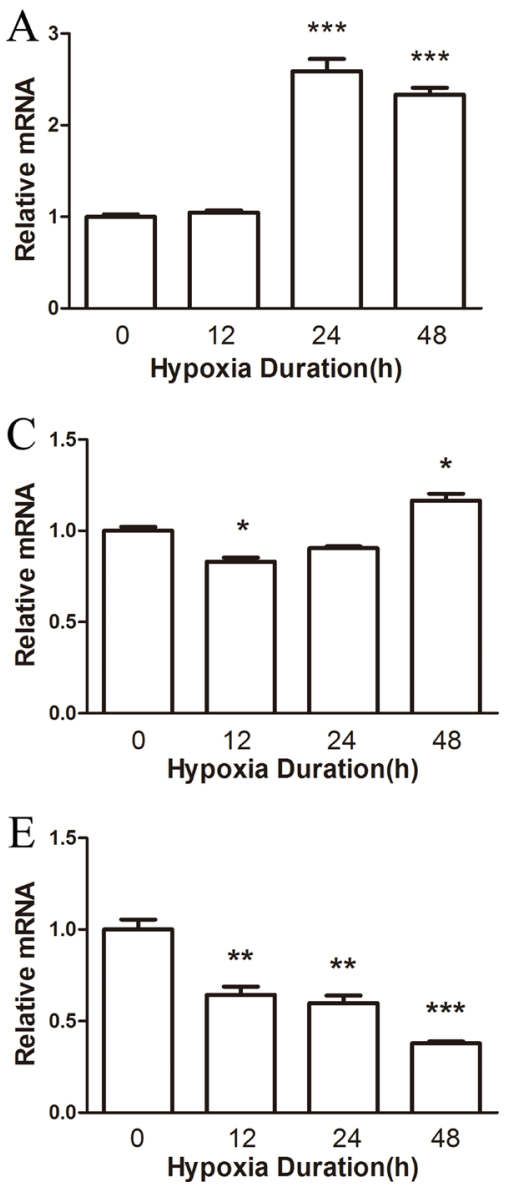

similar to the NRF1 and testosterone trends. As illustrated in Figure 5H, StAR showed a significant increase (2.25 fold under normoxia and 2.3-fold under hypoxia), similar to the NRF1 level.

To identify the in vivo binding of NRF1 to StAR promoter, we used the CHIP analysis and amplified the sequence ranging from -450 to -20 . Amplicons containing the already characterized NRF1 sites in the cyt c promoter were used as a positive control [15].

As shown in Figure 6, immunoprecipitated StAR promoter fragments were obtained using specific NRF1 antibody in both normoxia and hypoxia groups, with respect to IgG antibody control samples. The specificity of the enrichment obtained for the analyzed promoter was confirmed by the presence of a significant signal depending on NRF1 antibodies using cyt c primers. The ChIP assay confirmed that NRF1 binding sites existed in the StAR promoter. The binding sequences of NRF1 to the StAR promoter was determined from $-600-+25$.

To confirm that NRF1 decreased StAR gene transcription under hypoxia condition, we determined StAR expression in vitro and in vivo after hypoxia treatments. The primary Leydig cells were under hypoxia treatment
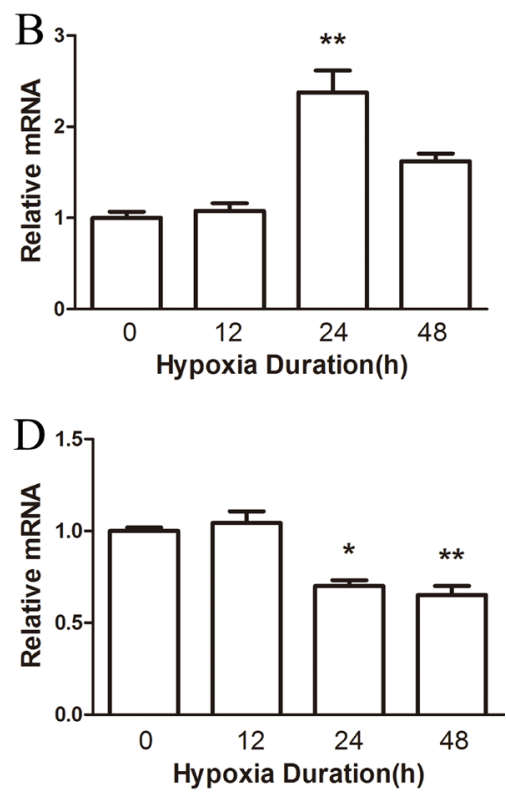

Figure 1: The mRNA level of NRF1 on different tissues after hypoxia treatment $\left(8 \% \mathrm{O}_{2}\right)$ for $0,12,24$ and $48 \mathrm{~h}$. The mRNA level of NRF1 in the heart (A), liver (B) and brain (C) increased after hypoxia treatment of male Balb/c mice. In the lung (D) and testis (E), NRF1 significantly decreased. $n=10$, mean \pm SD. ${ }^{*} p<0.05,{ }^{*} p<0.01,{ }^{* * *} p<0.001$. 
A

$0 \mathrm{~h} \quad 12 \mathrm{~h} \quad 24 \mathrm{~h} \quad 48 \mathrm{~h}$

NRF 1 -

$\beta$-actin

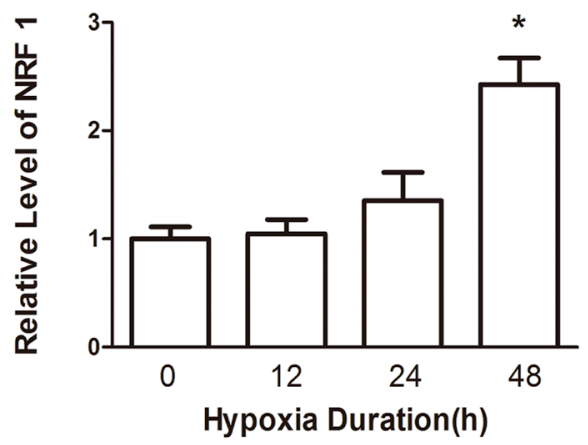

C
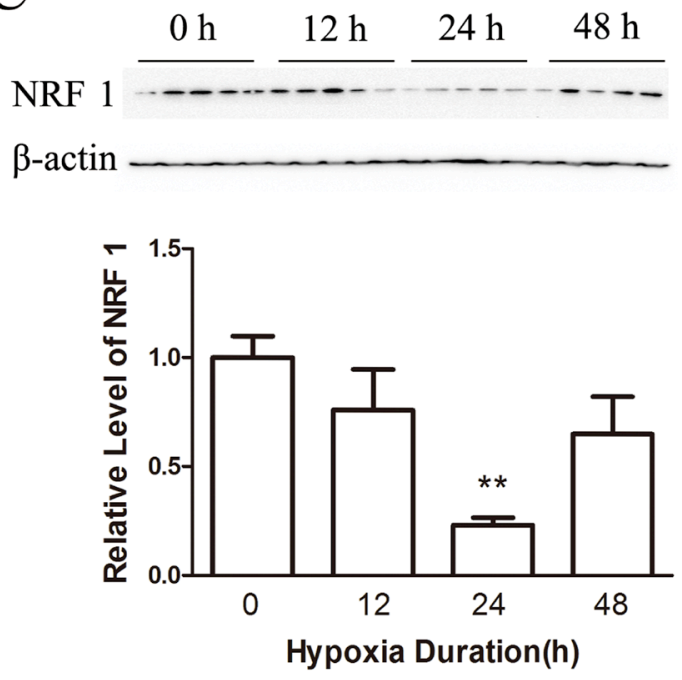

E
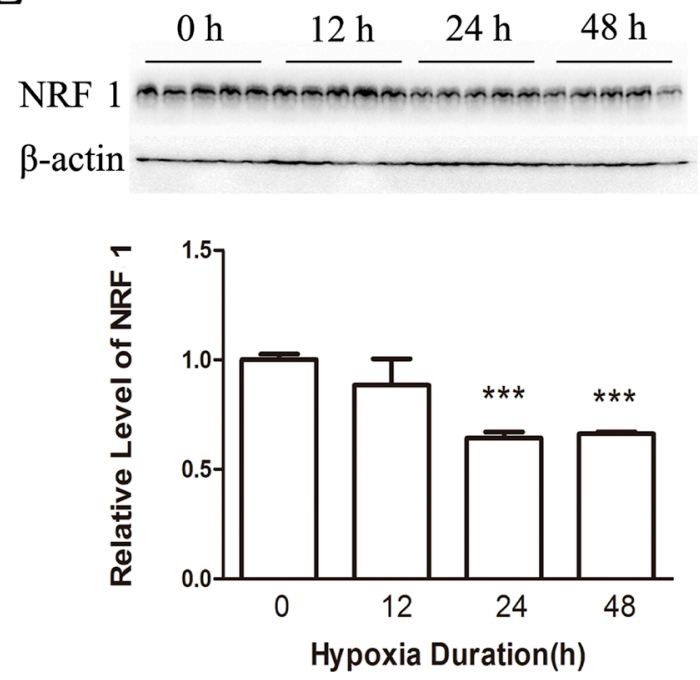
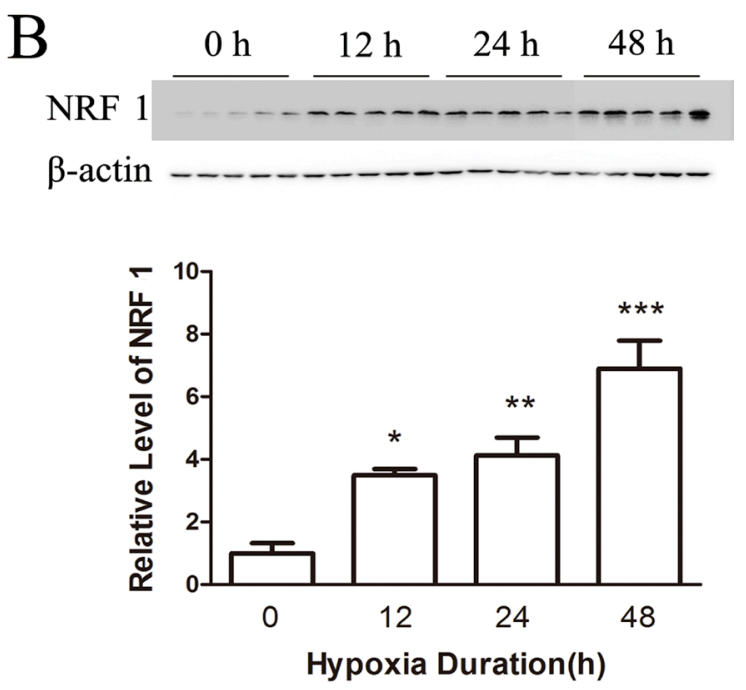

$\mathrm{D}$

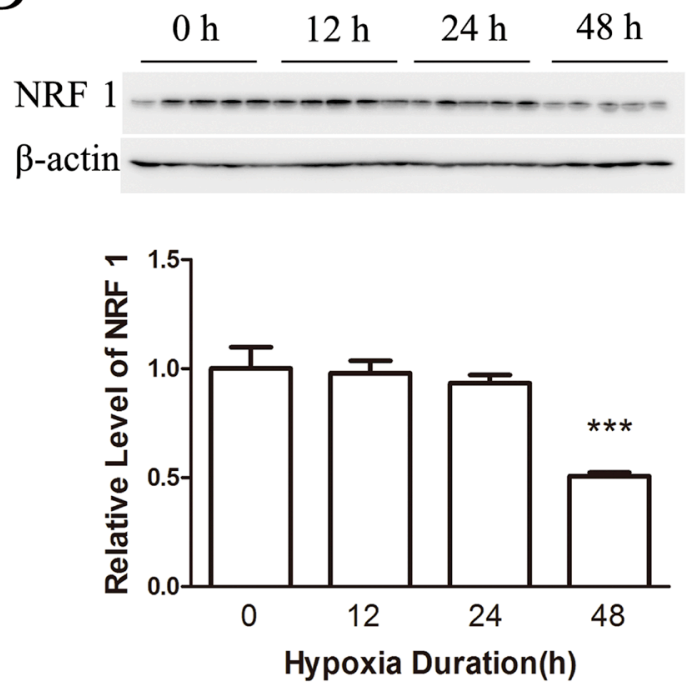

Figure 2: The protein level of NRF1 on different tissues after hypoxia treatment $\left(8 \% \mathrm{O}_{2}\right)$ for $0,12,24$ and $48 \mathrm{~h}$. The protein level of NRF1 in the heart (A) and liver (B) increased after hypoxia treatment of male Balb/c mice. In the brain (C), lung (D) and testis (E), NRF1 significantly decreased. $n=10$, mean \pm SD. ${ }^{*} p<0.05,{ }^{*} p<0.01,{ }^{* * *} p<0.001$. 
for $0,12,24,48$ hours and StAR was detected. Results show that the expression of StAR was decreased at both the mRNA and the protein level after hypoxia treatment (Figure 7), which was consistent with the changes of NRF1 (Figure 4A and 4B). Besides, the immunofluorescence results also suggested StAR decreased in Leydig cells in vivo after hypoxia treatment (Figure 8).

\section{DISCUSSION}

Snoring is the most common hypoxia status people experience when in sleep. Also, people working in offices tend to keep seated for long periods of time, which slows blood circulation to create hypoxia. Studies have shown that hypoxia affected respiratory, circulatory and endocrine systems [16, 17]. Hypoxia reduced the weight of thyroid [18], affected the function of hypothalamus-pituitaryadrenal axis [19], raised adrenocorticotropic hormone level [20]. Liao et al. reported high altitude hypoxia induced a significant reduction in the level of testosterone in male rats [21]. Hwang et al. found acute hypoxia upregulated testosterone release, on the contrary, chronic hypoxia downregulated testosterone release [22]. Madrid et al. in 2013 reported that high-altitude hypoxia induced plasmatic and testicular testosterone decreased from the 5 th day [5]. Liu et al. reported in 2012 that in hypoxic rats, serum testosterone levels decreased and mRNA and protein expressions of testosterone biosynthesis related genes downregulated [23]. In this study, we determined the hypoxia effects on testosterone in Balb/c mouse serum and primary Leydig cells. Results showed a similar trend that hypoxia reduced the testosterone level, consistent with those previous reports.

Although early studies have indicated that hypoxia had a serious impact on the endocrine system, there are few reports about the mechanism of the testosterone

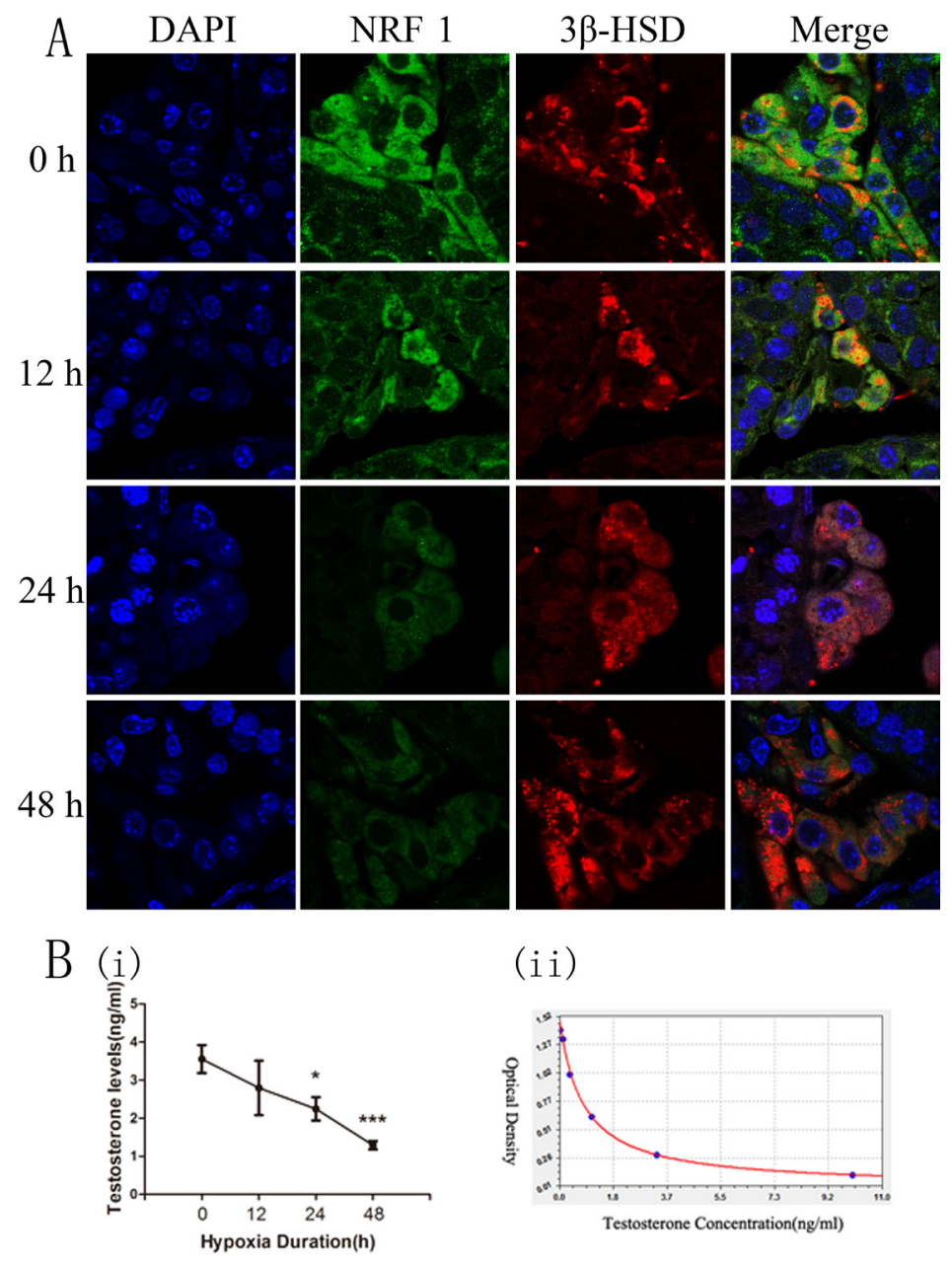

Figure 3: The expression of NRF1 in testis and the serum testosterone concentration of mice after hypoxia treatment $\left(8 \% \mathrm{O}_{2}\right)$ for $\mathbf{0 , 1 2 ,} 24$ and 48 h. (A) NRF1 in Leydig cells in mice was expressed in cytoplasm and NRF1 significantly decreased after hypoxia treatment. Blue fluorescence represented cell nucleus of testicular sections stained by DAPI, red fluorescence indicated the location of the Leydig cells by $3 \beta$-HSD and green fluorescence represented NRF1 protein. (B) ELISA results showed that the serum testosterone levels were lower under hypoxia situation. $n=10$, mean \pm SD. $* p<0.05, * * * p<0.001$ (i). ELISA Kit standard curve accords with Logistic curve, $r=0.99953991$ (ii). 
reduction induced by hypoxia. Satoh et al. identified 2,470 protein-coding genes in SK-N-SH human neuroblastoma cells, in whose promoter regions existed the NRF1binding consensus sequence. All those genes played a pivotal role in regulation of extra-mitochondrial biological processes, including splicing, cell cycle, RNA metabolism, protein translation initiation, DNA damage repair, and ubiquitin-mediated protein degradation [26]. Our previous studies firstly reported that NRF1 targeted HIF-1 $\alpha$ and repressed hif-1 $\alpha$ transcription [24], indicating NRF1 might be another important factor of hypoxia response. To evaluate the effect of NRF1 on testosterone synthesis, we overexpressed NRF1 with an overexpression plasmid and silencing NRF1 by transfection of NRF1 small interfering RNAs, and then detected testosterone concentration in supernatant of TM3 cells. No matter under normoxia or hypoxia condition, testosterone concentration was along with the change of NRF1 level (Figure 5). We tried to knock out NRF1 in HEK 293T cells using the CRISPR/ Cas 9 method to find cells with complete loss of NRF1 unable to survive (data not shown). There are no reports about NRF1 knock out mice, we suppose NRF1 knock out is lethal to both cells and animals.

In our previous study, we found testosterone
A

(i)

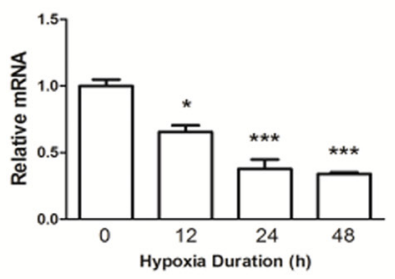

(ii)

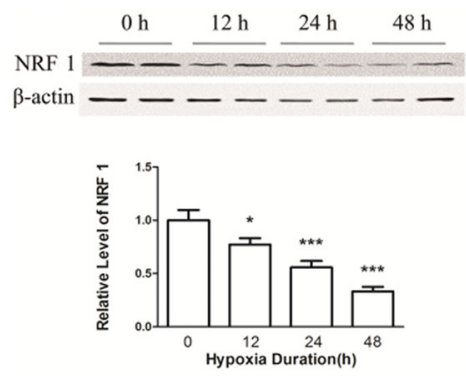

C

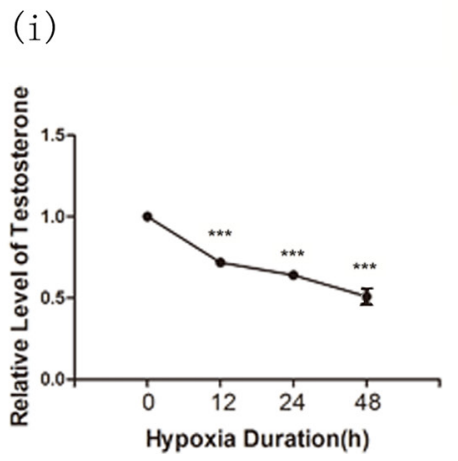

$\mathrm{B}$

$0 \mathrm{~h}$

$12 \mathrm{~h}$

$24 \mathrm{~h}$

$48 \mathrm{~h}$

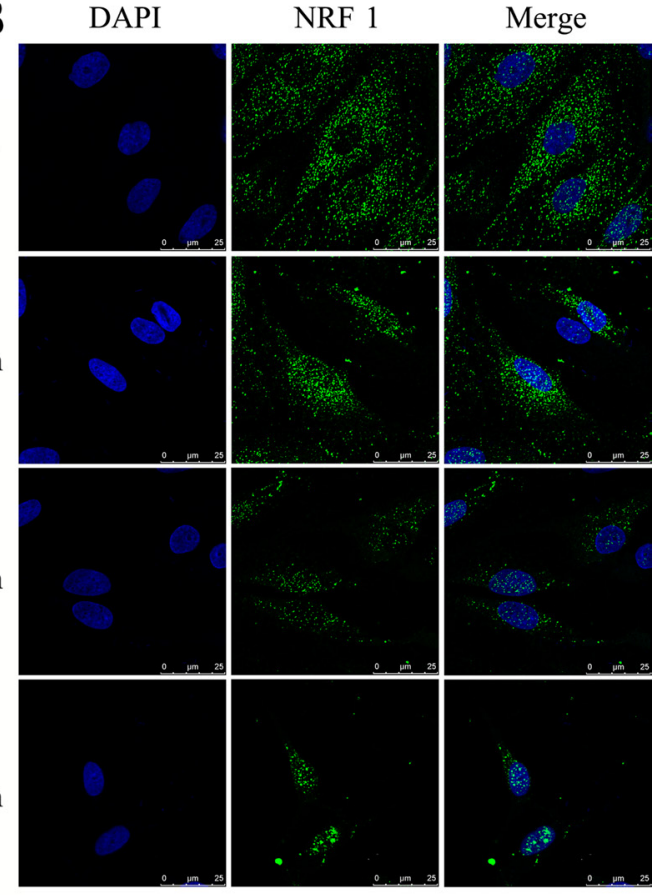

(ii)

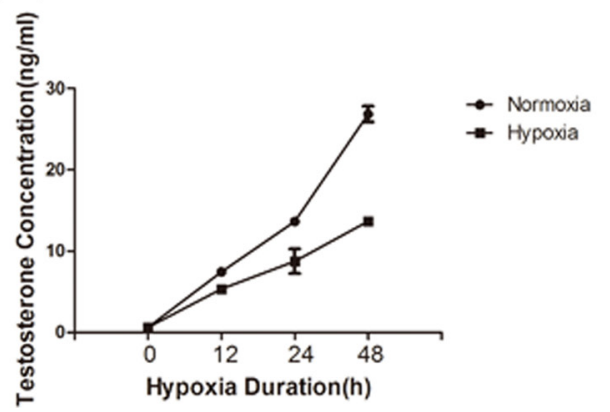

Figure 4: NRF1 levels and the testosterone concentration in the supernatant of primary cultured Leydig cells after hypoxia treatment $\left(1 \% O_{2}\right)$ for $0,12,24$ and $48 \mathrm{~h}$. (A) The mRNA expressions of NRF1 were decreased after hypoxia treatments. $n=6$, mean \pm SD. ${ }^{*} p<0.05,{ }^{*} p<0.01$ (i). The protein levels of NRF1 were decreased after hypoxia treatments. $n=6$, mean \pm SD. ${ }^{*} p<0.05,{ }^{* * *} p<0.001$ (ii). (B) The expression of NRF1 on the Leydig cells was decreased after hypoxia treatment. Blue fluorescence represented nucleus of Leydig cells by DAPI and green fluorescence represented NRF1 protein. (C) Relative level of testosterone under hypoxia comparing to normoxia. ELISA results showed that the serum testosterone levels were lower under hypoxia situation $n=5$, mean \pm SD., ${ }^{* * *} p<0.001$ (i). The concentration of testosterone under hypoxia and normoxia condition. $n=5$, mean \pm SD. (ii). ELISA Kit standard curve accords with Logistic curve, $r=0.99953991$ (iii). 
released by TM3 cells increased under hypoxia, which was opposite to the results of in vivo and the primary Leydig cells. But the results consisted with the report of Hwang et al. in 2007. They found that TM3 cells synthesized testosterone in need of hCG stimulation, which increased vascular endothelial growth factor (VEGF) production

A

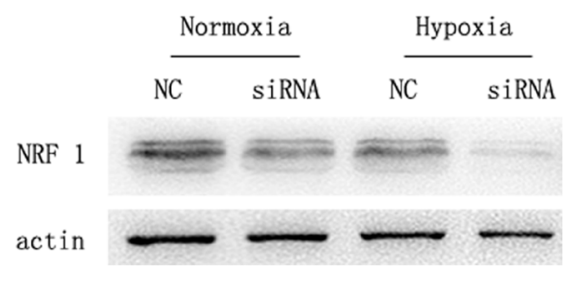

C

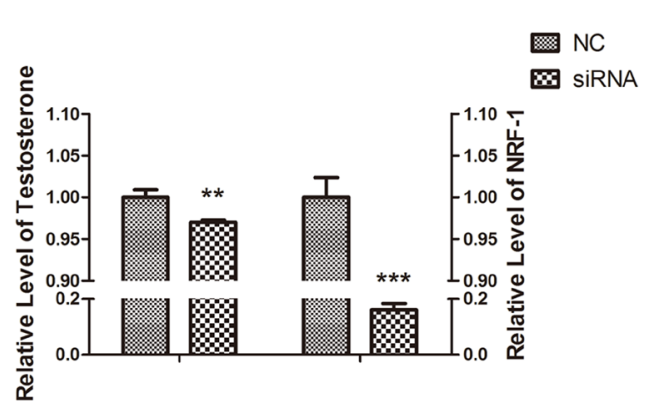

E

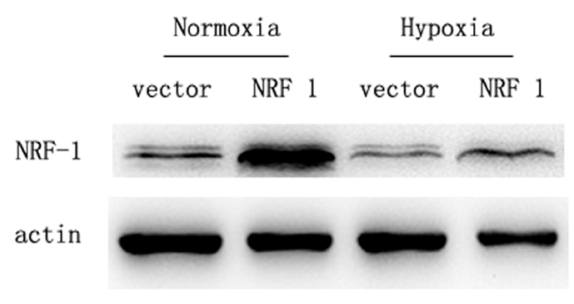

G

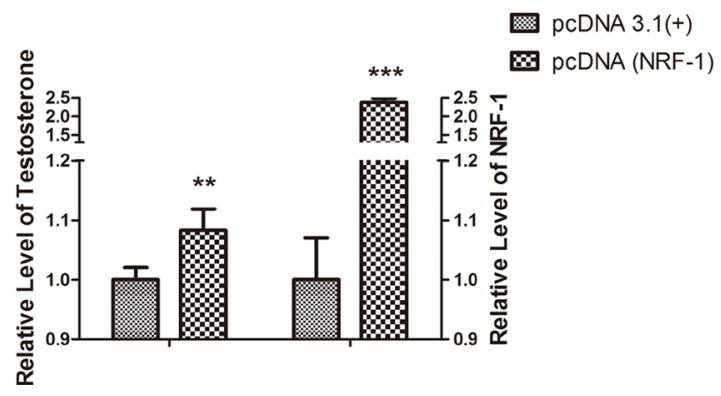

under hypoxia condition, leading to the testosterone increase. This stimulatory effect was abolished by the administration of anti-VEGF antibody [25]. Minet et al. reported hCG stimulated ERK 1/2 phosphorylation, upregulating the testosterone level in TM3 cells [26]. Results indicated that TM3 cells were not an ideal model

B

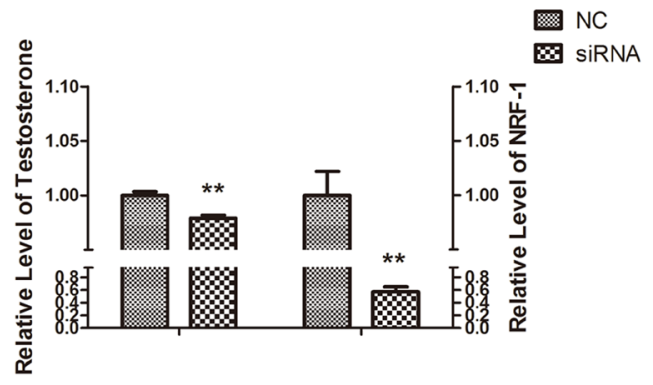

D

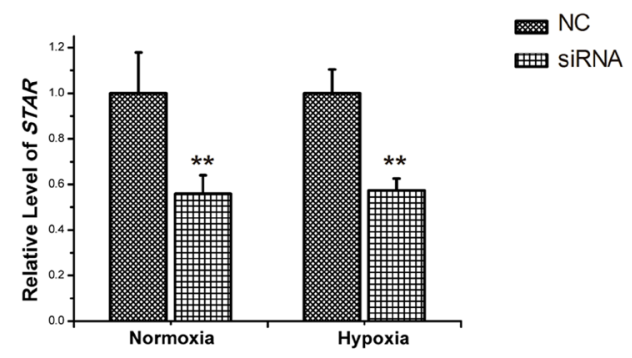

F

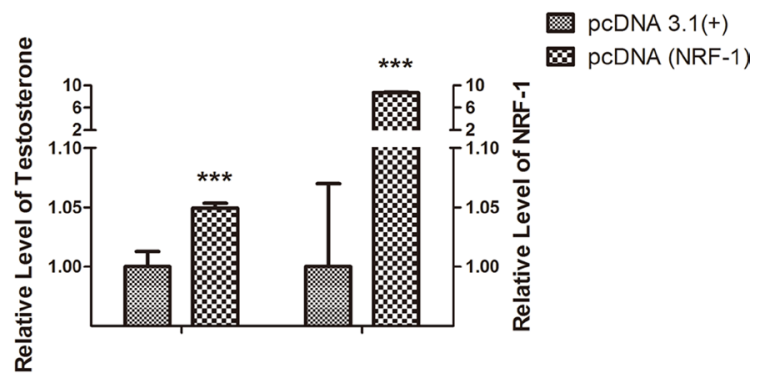

H

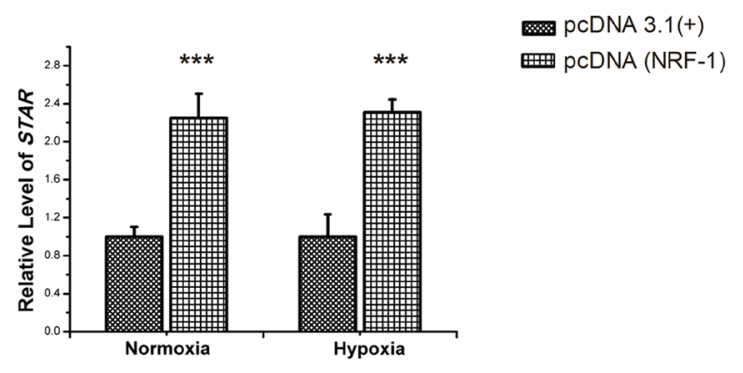

Figure 5: Testosterone release and StAR level of TM3 cells after the regulation of NRF1 under normoxia or hypoxia $\left(\mathbf{1 \%} \mathrm{O}_{2}, \mathbf{2 4} \mathbf{h}\right)$. NRF1 silencing in TM3 (A) markedly downregulated the release of testosterone under both normoxia (B) and hypoxia (C) environment, while the StAR expression followed the same trend (D). Overexpression of NRF1 (E) resulted in a higher testosterone release under both normoxia $(\mathbf{F})$ and hypoxia $(\mathbf{G})$ environment. Expressions of StAR showed the same trends $(\mathbf{H}) . n=5$, mean $\pm \mathrm{SD}$., $* * p<0.01, * * * p<0.001$. 


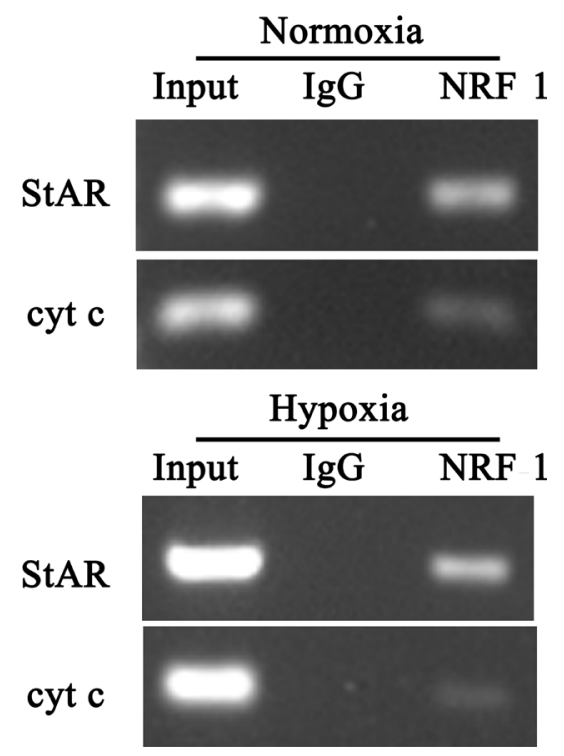

Figure 6: ChIP analysis for StAR promoter region. Anti-NRF1 antibody was used for the ChIP assay and quantification of immunoprecipitated DNA fragments was performed by real-time PCR. The PCR product was obtained from the chromatin without immunoprecipitation reaction as group Input and IgG was as negative control. ChIP confirmation of occupancy of the NRF1 in StAR gene promoters using antibody against NRF1under normoxia or hypoxia $\left(1 \% \mathrm{O}_{2}\right)$ for 24 hours.
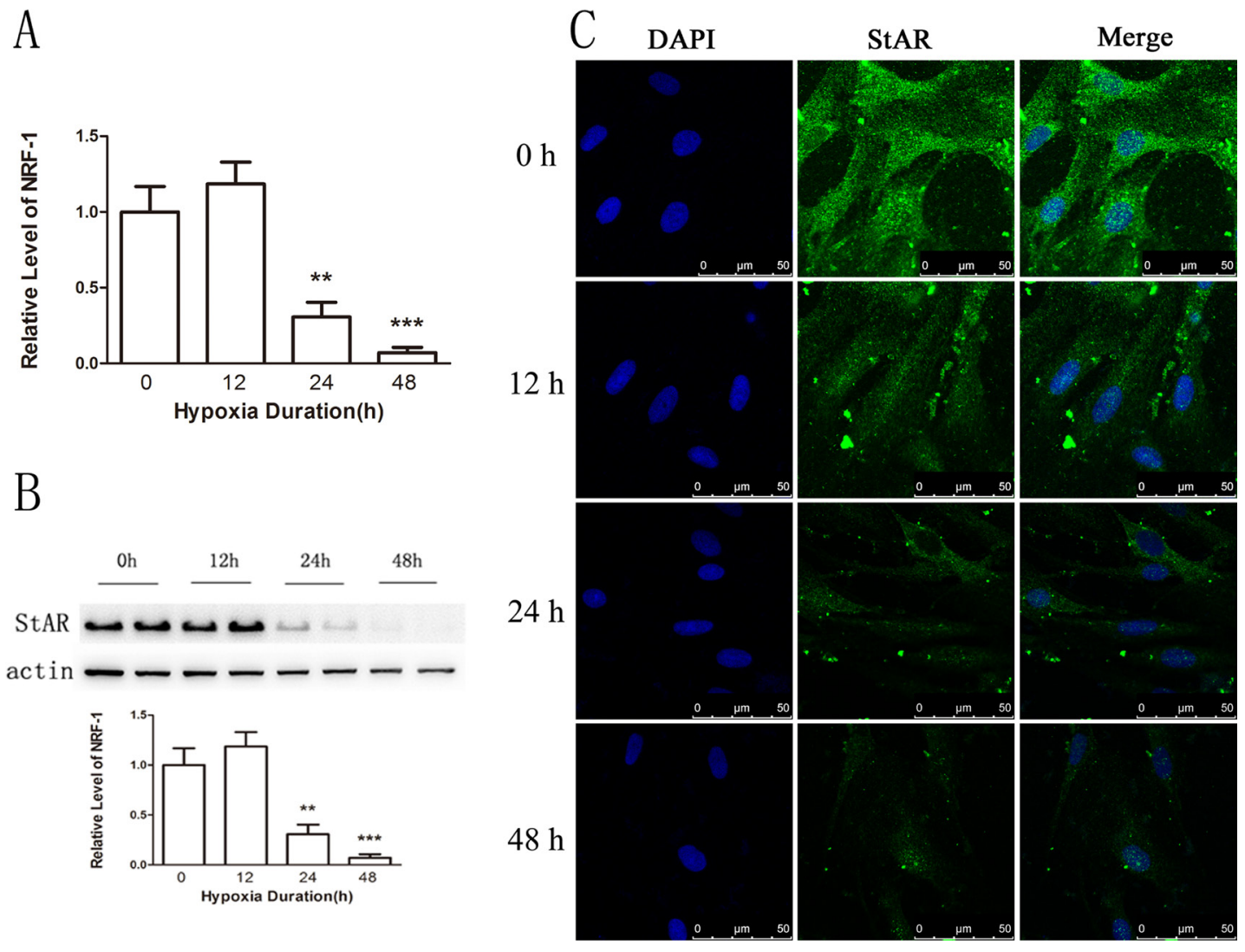

Figure 7: The expression of StAR on primary Leydig cells. (A) The expression of StAR was decreased at the mRNA level. $n=6$, mean \pm SEM. ${ }^{* *} p<0.01,{ }^{* * *} p<0.001$. (B) The expression was decreased on the protein level. $n=6$, mean \pm SEM. ${ }^{*} p<0.01, * * * p<0.001$. (C) The expression of StAR on the Leydig cells was decreased after hypoxia treatment. Blue color represented testicular sections counterstained by DAPI and green fluorescence represented StAR protein. 
to study the hypoxia response of Leydig cells, since hCG "covered up" the actual effect of hypoxia.

Another interesting problem is how NRF1 affected testosterone synthesis. Bioinformatics analysis revealed that 5 testosterone synthesis related genes, whose promoter region had the potential binding site of NRF1, including Insulin-like 3, Nur 77, Peripheral-type benzodiazepine receptor (PBR), 3 $\beta$-HSD and StAR. Primary experiments indicated that StAR was reduced most significantly under hypoxia, while other enzymes like $3 \beta$-HSD did not show such reduction. Insulin-like 3 is a peptide hormone in male mammals secreting by adult Leydig cells [27]. Insulinlike 3 was independent of control via gonadal hormone, functioning like an anti-apoptotic or survival factor in germ cells in the testis and ovary [28]. Nur77 has been shown to stimulate genes involved in steroidogenesis in Leydig cells, including StAR and 3 $\beta$-HSD [29]. In Leydig cells, PBR co-act with StAR mediated cholesterol transfer into mitochondria [11]. The transferation of cholesterol is a rate-limiting step of testosterone synthesis, and StAR is the rate limiting protein of this process $[12,13]$, which is the protein of interest for its role in hypoxia-induced testosterone reduction. In vivo and in vitro experiments verified that StAR decreased in trends of NRF1 under hypoxia (Figures 7 and 8). ChIP analysis confirmed that NRF1 bond to StAR promoter region (Figure 6).

Some studies focused on the role of hypoxia in StAR. Liu et al reported in 2012 that in hypoxic rats, expression StAR and 3 $\beta$-HSD were downregulated [23]. Su et al. reported that increases in plasma leptin inhibited the expression of StAR and steroidogenic enzymes and attenuate adrenal responsiveness in hypoxic fetuses [30]. Zhang et al. reported that an activated NADPH downregulated StAR expression in the hypoxia testis, inducing testicular damage [31]. Kowalewski et al. found inhibition of expression of HIF-1 $\alpha$ suppressed StAR expression. HIF-1 $\alpha$ appeared to be a positive regulator of StAR [32]. Our work found NRF1 promoted StAR expression under normoxia and hypoxia for the first time. The downregulation of StAR caused by lower NRF1 was the reason of, at least in part, testosterone reduction under hypoxia.

In Figure 1, it was shown that NRF1 in different tissues had different changes after hypoxia treatment. It might because of the complicate function of NRF1 in

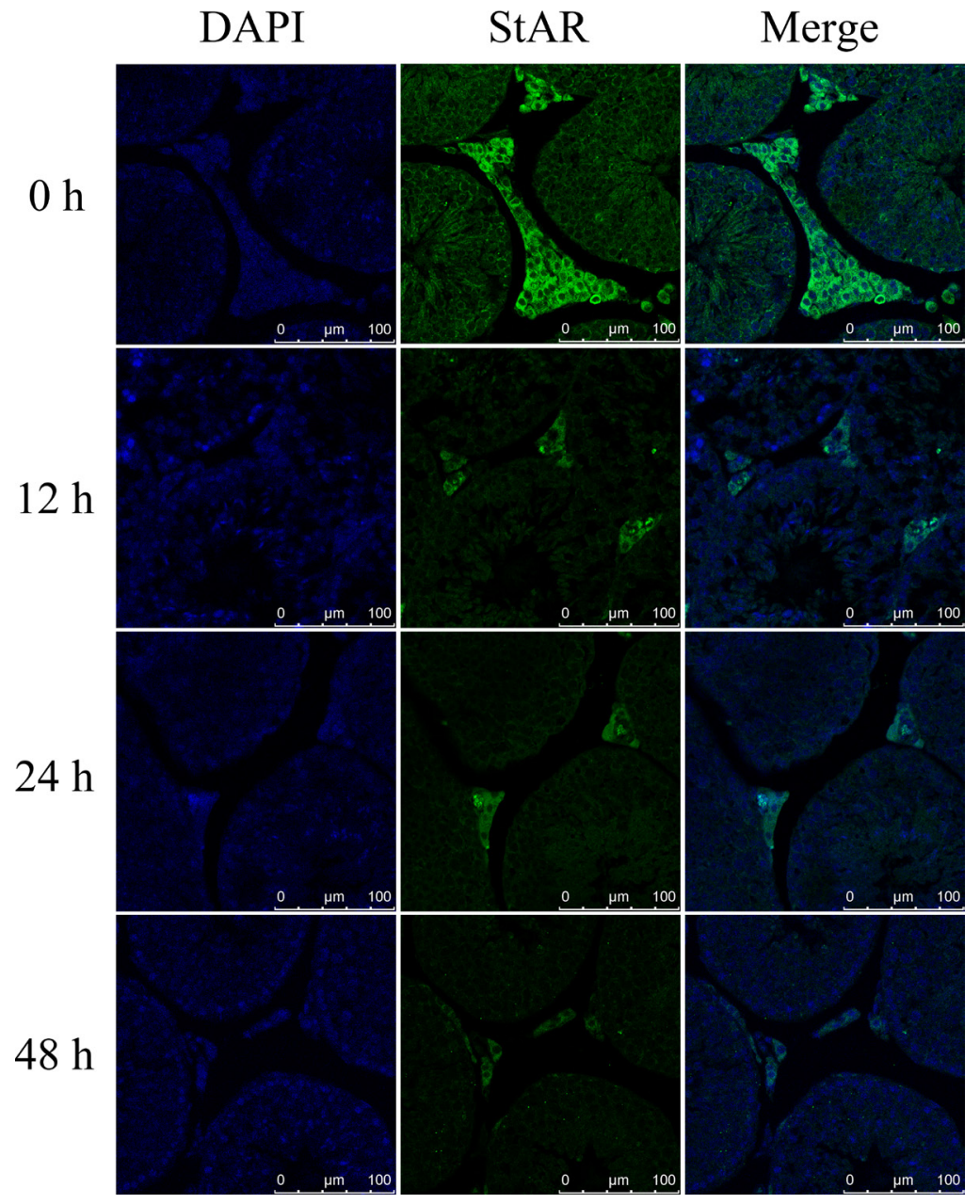

Figure 8: The expression of StAR in Leydig cells in vivo after hypoxia treatment. Blue color represented testicular sections counterstained by DAPI and green fluorescence represented StAR protein. 
different tissues. The reasons of those different changes and the possible results caused by NRF1 were not revealed in this work. Considering the important role of NRF1 played in cells, its reduction should cause a lot of damages to Leydig cells. There are questions remaining to be answered, including what proteins are affected, how the mitochondria will respond, and what is the fate of Leydig cells along with the hypoxia duration.

\section{MATERIALS AND METHODS}

\section{Animals and treatment}

Male Balb/c mice $(n=60)$ weighing 20-25 g were supplied from Experimental Animal Center of Nantong University, China. All these mice were accommodated for one week before experiments with a 12 h:12 h light-dark cycle, and then were randomly divided into 4 groups with 15 mice per group: normoxia control group and 12, 24, 48 hypoxia condition group. Mice were confined in a sealed container in which $8 \%$ oxygen concentration were supplied for $0,12,24,48 \mathrm{~h}$. Then all animals were anaesthetized by $10 \%$ chloral hydrate with intraperitoneal injection. For the 10 mice in each group, blood samples were obtained from abdominal aorta, and samples of testis tissues were harvested for real-time PCR and Western Blot. Hearts of the other 5 mice in each group were instilled in vivo with $4 \%$ citromint. Testis paraffin section was made to observe the Immunofluorescence staining.

All the studies reported here was submitted to ethics committee on animal experimentation in Nantong University and all procedures were approved according to the Animal Care and Use Committee of Nantong University and the Jiangsu Province Animal Care Ethics Committee (Approval ID: SYXK(SU)2007-0021).

\section{Isolation and treatment of primary Leydig cells}

The method used for the isolation and purification of Leydig cells was modified from one previously described for testis Leydig cells extraction [33]. Briefly, decapsulated Balb-c mice testes were immersed in $0.1 \%$ collagenase-PBS and were shaken for $30 \mathrm{~min}$ at $200 \mathrm{rpm}$, $37^{\circ} \mathrm{C}$. After dissociation, the seminiferous tubules were removed by filtration through the wire on the mesh 200 to get cells suspension. The filtrate was centrifuged at 1200 rpm for $7 \mathrm{~min}$ at $4^{\circ} \mathrm{C}$ and cells were collected into medium of 27:3:20 (v/v/v) of Percoll: $9 \% \mathrm{NaCl}$ saline solution: DMEM-F12 medium (Hyclone, GE Healthcare Life Sciences, Logan, Utah) and centrifuged at 20,000 $\times \mathrm{g}$ for $60 \mathrm{~min}$ at $4^{\circ} \mathrm{C}$. Cells were resuspended at $5 \times 10^{5}$ cells $/ \mathrm{ml}$ in DMEM-F12 medium containing 5\% Newborn Calf Serum (Gibco, Grand Island, New York) for subsequent analysis. The collected cells were characterized with immunofluorescence stainning. More than $98 \%$ of the visualized cells were positive.
Finally, cells were added into $35 \mathrm{~mm}$ dishes containing $5 \mathrm{ml}$ culture medium and maintained at $34^{\circ} \mathrm{C}$ in humidified atmosphere composed of $95 \%$ air, $5 \% \mathrm{CO}_{2}$. After $12 \mathrm{~h}$ adherence, the dishes were divided into 4 groups receiving $1 \% \mathrm{O}_{2}, 5 \% \mathrm{CO}_{2}$ incubation for $0,12,24,48 \mathrm{~h}$ in an Invivo $_{4}$ hypoxia chamber (Ruskinn Technologies, Leeds, UK). Cell supernatants were collected for testosterone concentration assay. Protein and mRNA were extracted for Western blot and real-time PCR.

\section{Culture and treatment of TM3 cells}

TM3 cells (CRL-1714, ATCC, RRID:CVCL_4326) were a kind of non-tumorigenic cell line derived from mouse testis, which secret testosterone in response to Luteinizing hormone ( $\mathrm{LH})$ and human Chorionic gonadotropin (hCG). The mechanism is similar to primary Leydig cells. Cells were characterized with immunofluorescence staining. Cells were cultured in 1:1 mixture of Ham-12 and Dulbecco's MEM (Hyclone, GE Healthcare Life Scinces, Logan, Utah), containing 5\% horse serum (Gibco, Grand Island, New York), 2.5 \% Fetal Bovine Serum (Hyclone, GE Healthcare Life Scinces, Logan, Utah), in $35 \mathrm{~mm}$ dishes. Cells were cultured at $37^{\circ} \mathrm{C}$ in humidified atmosphere composed of $95 \%$ air, $5 \% \mathrm{CO}_{2}$. After $12 \mathrm{~h}$ adherence, the dishes were divided into 4 groups receiving $1 \% \mathrm{O}_{2}, 5 \% \mathrm{CO}_{2}$ incubation for $0,12,24,48 \mathrm{~h}$ in an Invivo $_{4}$ hypoxia chamber (Ruskinn Technologies, Leeds, UK). Cell supernatants were collected for testosterone concentration assay. Protein and mRNA were extracted for Western blot and real-time PCR.

\section{Testosterone concentration assay}

Blood samples were placed in $1.5 \mathrm{~mL}$ microcentrifuge tubes at room temperature for $2 \mathrm{~h}$ and centrifuged at $2000 \mathrm{rpm}$ for $20 \mathrm{~min}$ to collect serum. Testosterone concentration of both serum and cell supernatants was examined by a Parametre Testosterone Assay kit (KGE010, R\&D Systems, Minneapolis, Minnesota).

\section{Total RNA extraction and real-time PCR}

Total RNA was isolated from hypothalamus using Column Animal RNAout (TianDZ, Beijing, China) according to the manufacturer's instructions. Purified total RNA (500 ng) was then reverse-transcribed using HiScript 1st Strand cDNA Synthesis Kit (Vazyme, Nanjing, China).

The primer sequences used were shown in Supplementary Table 1. Briefly, amplification was subsequently carried out by mixing $1 \mu \mathrm{L}$ of cDNA product with $10 \mu \mathrm{L}$ of $2 \times$ FastStARt Universal SYBR Green Master (Roche Diagnostics, Mannheim, Germany), $2 \mu \mathrm{L}$ of the primer pair mix ( $2 \mathrm{mM}$ sense and $2 \mathrm{mM}$ antisense) and $7 \mu \mathrm{L}$ of RNase-free water. Real-time PCR was performed in Lightcycler 96 (Roche Diagnostics, IN, USA). 


\section{Total protein extraction and Western blot}

Harvested mouse testes, primary Leydig cells or TM3 cells were homogenized in the protein extraction buffer for extracting proteins. The homogenates were kept on ice for $30 \mathrm{~min}$ and centrifuged at 12,000 $\mathrm{g}$ for $30 \mathrm{~min}$. Supernatants were collected and protein concentrations were determined by the Bradford method. About $40 \mu \mathrm{g}$ of the extracted protein from each sample were separated by SDS-PAGE and electrophoretically transferred onto a PVDF membrane. Membranes were blocked in $2.5 \%$ BSA $+2.5 \%$ milk in TBS for $2 \mathrm{~h}$ at $37^{\circ} \mathrm{C}$. Blocked membranes were incubated with NRF1 polyclonal antibody (ab175932, Abcam, Hong Kong, China), beta-actin monoclonal antibody (ab8227, Abcam, USA) or StAR monoclonal antibody (8449, Cell Signaling Technology, Danvers, Massachusetts) in TBST containing 3\% BSA at $4^{\circ} \mathrm{C}$ overnight. Next, the membranes were washed 6 times with PBST, 5 min each time, followed by incubation for $1.5 \mathrm{~h}$ at room temperature with a secondary antibody (Jackson ImmunoResearch, West Grove, Pennsylvania) at a concentration of 1: 10000 in TBST containing 3\% BSA. The chemiluminescence reaction was performed using SuperSignal West Pico (Thermo Scientific, Rockford, IL).

\section{Immunofluorescence of testis paraffin sections}

The fixed testes were embedded in paraffin, sectioned at $5 \mu \mathrm{m}$ and dried at $37^{\circ} \mathrm{C}$ overnight. Tissue sections were immersed in fresh xylene for 5 min twice at room temperature. Sections were washed in $100 \%$ ethanol for $5 \mathrm{~min}$. Next, sections were rehydrated by sequentially immersing the slides through graded ethanol washes $(100 \%, 95 \%, 85 \%, 70 \%, 50 \%)$ for 3 min each. Then sections were washed in $0.85 \% \mathrm{NaCl}$ for $5 \mathrm{~min}$ and in PBS for 5 min. Samples were fixed in $4 \%$ methanolfree formaldehyde in PBS for 15 min followed by washing twice with PBS. Sections were blocked in 5\% BSA in PBS for $2 \mathrm{~h}$ at $37^{\circ} \mathrm{C}$. To detect NRF1 level, blocked sections were incubated with NRF1 mAB (ab175932, Abcam, Hong Kong, China) and 3 $\beta$-HSD mAB (sc-30820, Santa Cruz, USA), which was a marker of Leydig cells, in PBST containing $5 \%$ BSA at $4{ }^{\circ} \mathrm{C}$ overnight followed by washing with PBST 6 times for 5 min each time. Sections were incubated with Alexa Fluor 488-conjugated donkey antirabbit IgG (R37118, Life technologies Eugene, Oregon) and Alexa Fluor 555-conjugated donkey anti-goat IgG (A-21432, Life technologies, Eugene, Oregon) for $2 \mathrm{~h}$ at $37^{\circ} \mathrm{C}$ and were protected from light followed by washing 6 times with PBST for 5 min each time. Finally, the samples were stained with DAPI (Life technologies, Eugene, Oregon) as nuclear counterstain. To detect StAR level, blocked sections were incubated with StAR mAb (8449, Cell Signaling Technology, Danvers, Massachusetts) in PBST containing 5\% BSA at $4{ }^{\circ} \mathrm{C}$ overnight followed by washing with PBST 6 times for 5 min each time. Sections were incubated with Alexa Fluor 488-conjugated donkey anti-rabbit IgG (R37118, Life technologies, Eugene, Oregon) for $2 \mathrm{~h}$ at $37^{\circ} \mathrm{C}$ and were protected from light followed by washing 6 times with PBST for 5 min each time. Finally, the samples were stained with DAPI (Life technologies, Eugene, Oregon) as nuclear counterstain. The samples were analyzed with a microscope (Leica, SP8) for the detection.

\section{Immunocytochemistry of primary Leydig cells and TM3 cells}

Cells were crawled on the slide and incubated with $1 \% \mathrm{O} 2$ for $0,12,24$ and $48 \mathrm{~h}$. Then slides were fixed in 4\% methanol-free formaldehyde in PBS for 15 min followed by washing twice with PBS. Slides were blocked in $5 \%$ BSA in PBS for $2 \mathrm{~h}$ at $37^{\circ} \mathrm{C}$. Blocked samples were incubated with StAR mAb (8449, Cell Signaling Technology, Danvers, Massachusetts) or NRF1 mAB (ab175932, Abcam, Hong Kong, China) in PBST containing $5 \% \mathrm{BSA}$ at $4{ }^{\circ} \mathrm{C}$ overnight followed by washing with PBST 6 times for 5 min each time. Samples were incubated with Alexa Fluor 488-conjugated donkey antirabbit IgG (1723091, Life technologies, Eugene, Oregon) for $2 \mathrm{~h}$ at $37^{\circ} \mathrm{C}$ and were protected from light followed by washing 6 times with PBST for 5 min each time. Finally, the samples were stained with DAPI (Life technologies, Eugene, Oregon) as nuclear counterstain. The samples were analyzed with a microscope (Leica, SP8) for the detection.

\section{Chromatin immunoprecipitation}

Chromatin Immunoprecipitation (ChIP) was performed using the EZ-ChIP Kit (Millipore, Temecula, California, USA) according to the manufacturer's instructions. Briefly, TM3 cells were washed and fixed in culture medium containing $1 \%$ formaldehyde at room temperature for $10 \mathrm{~min}$. The cells were collected and lysed to release the nucleus. Nuclei were then isolated by centrifugation before being subjected to sonication. The sonicated lysate was then immunoprecipitated with $2 \mu \mathrm{g}$ of NRF1 antibodies (ab34682, Abcam, Hong Kong, China) , or a negative control $\operatorname{IgG}$ at $4{ }^{\circ} \mathrm{C}$ for $4 \mathrm{~h}$. The pulled-down chromatin was washed, reverse-cross linked and purified. To the detection of the target gene StAR and the positive control cyt c, PCR reactions were performed using 5\% of precipitated chromatin. Primers targeting promoter sequences were shown in Supplementary Table 2.

\section{Over expression or gene silencing of NRF1}

The expression plasmids for wildtype NRF1 were constructed according to a method described previously [34]. All constructs were verified by sequencing. TM3 cells were seeded into 6- or 24-well plates in antibiotic-free 
medium the day before transfection. Each well of cells was transiently transfected plasmids using X-tremeGENE HP DNA Transfection Reagent (Roche Diagnostics, IN, USA). Experiments for gene silencing were performed using small interfering NRF1 (siRNA-NRF1). Mouse NRF1 specific siRNA duplex were designed and synthesized by Dharmacon (Dharmacon, Lafayette, CO, USA). X-treme GENE siRNA transfection reagent (Roche Diagnostics, IN, USA) was used for transfection following the manufacturer's protocol.

\section{Statistical analysis}

Results are represented as means $\pm \mathrm{SD}$ from three independent experiments. Statistical significance was determined by one-way ANOVA, followed by the post-hoc Tukey multiple comparison test.

\section{Abbreviations}

NRF1, nuclear respiratory factor 1; StAR, steroidogenic acute regulatory protein; $3 \beta-\mathrm{HSD}$, $3 \beta$-hydroxysteroid dehydrogenase; 17 $\beta$-HSD, 17 $\beta$-hydroxysteroid dehydrogenase; ChIP, chromatin immunoprecipitation; LH, Luteinizing hormone; hCG, Human Chorionic gonadotropin; VEGF, vascular endothelial growth factor; PBR, peripheral-type benzodiazepine receptor.

\section{ACKNOWLEDGMENTS}

We received considerable technical assistance from Dr. Zhongping Chen, Dr. Jiapeng Tang, Zhenqing Qian, Bo Wang and Jie Zhang.

\section{CONFLICTS OF INTEREST}

The authors have no conflicts of interest to declare.

\section{FUNDING}

This study was supported by the National Natural Science Foundation of China (31471141, 31671206, $31500965)$, the priority Academic Program Development of Jiangsu Higher Education Institution (PAPD), University Science Research Project of Jiangsu Province (15KJB180012), and the Natural Science Foundation of Jiangsu Province (BK20150404, BK20140574).

\section{Authors' contributions}

XW and LZ conceived and designed the study. XW, LP and ZZ performed the experiments. XW and LP wrote the manuscript. DW provided the plasmids. YL and ZD reviewed and edited the manuscript. All authors read and approved the manuscript.

\section{REFERENCES}

1. Kamali M, Baghestani AR, Kashfi F, Kashani H, Tavajohi S, Amirchaghmaghi E. A survey on infertility in Royan Institute. Iran J fertile Steril. 2007; 1:23-26.

2. Okumura A, Fuse. H, Kawauchi Y, Mizuno. I, Akashi T. Changes in male reproductive function after high altitude mountaineering. High Alt Med Biol. 2003; 4:349-353. doi: 10.1089/152702903769192304.

3. Liao W, Cai M, Chen J, Huang J, Liu F, Jiang C, Gao Y. Hypobaric hypoxia causes deleterious effects on spermatogenesis in rats. Reproduction. 2010; 139:1031-1038. doi: 10.1530/REP-09-0557.

4. Paul C, Teng S, Saunders PTK. A Single, Mild, Transient scrotal heat stress causes hypoxia and oxidativestress in mouse testes, which induces germ cell death. Biol Reprod. 2009; 80:913-919. doi: 10.1095/biolreprod.108.071779.

5. Madrid EM, Reyes JG, Hernández B, García JMH, Martin SS, Olivero P, Crespo PV, Párraga M. Effect of normobaric hypoxia on the testis in a murine model. Andrologia. 2013; 45:332-338. doi: 10.1111/and.12019.

6. Akishita M, Yu J. Hormonal effects on blood vessels. Hypertens Res. 2012; 35:363-369. doi: 10.1038/hr.2012.4.

7. Maddalena CD, Vodo S, Petroni A, Aloisi AM. Impact of testosterone on body fat composition. J Cell Physiol. 2012; 227:3744-3748. doi: 10.1002/jcp.24096.

8. Morales A, Bella AJ, Chun S, Lee J, Assimakopoulos P, Bebb R, Gottesman I, Alarie P, Dugré H, Elliott S. A practical guide to diagnosis, management and treatment of testosterone deficiency for Canadian physicians. Can Urol Assoc J. 2010; 4:269-275. doi: 10.5489/cuaj.880.

9. Jang M-K, Son Y, Jung MH. ATF3 plays a role in adipocyte hypoxia-mediated mitochondria dysfunction in obesity. Biochem Biophys Res Commun. 2013; 431:421-427. doi: 10.1016/j.bbrc.2012.12.154.

10. Escrivzi H, Rodrfguez-Pefia A, Vallejo CG. Expression of mitochondrial genes and of the transcription factors involved in the biogenesis of mitochondria Tfam, NRF1 and NRF-2, in rat liver, testis and brain. Biochimie. 1999; 81:965-971. doi: 10.1016/S0300-9084(99)00223-0.

11. Payne AH, Hardy MP. Structural and Histological Analysis of Leydig Cell Steroidogenic Function. The Leydig Cell in Health and Disease. 2007; 33-35.

12. Clark BJ, Wells J, King SR, Stocco DM. The purification, cloning, and expression of a novel luteinizing hormoneinduced mitochondrial protein in MA-10 mouse Leydig tumor cells. Characterization of the steroidogenic acute regulatory protein (StAR). J Biol Chem. 1994; 269:2831428322.

13. Miller WL, Auchus RJ. The molecular biology, biochemistry, and physiology of human steroidogenesis and its disorders. Endocr Rev. 2011; 32:81-151. doi: 10.1210/er.2010-0013.

14. Piantadosi CA,Suliman HB. Transcriptional Regulation of SDHa flavoprotein by nuclear respiratory factor-1 prevents 
pseudo-hypoxia in aerobic cardiac cells. J Biol Chem. 2008; 283:10967-10977. doi: 10.1074/jbc.M709741200.

15. Hossain MB, Ji P, Anish R, Jacobson RH, Takada S. Poly(ADP-ribose) Polymerase 1 Interacts with Nuclear Respiratory Factor 1 (NRF1) and Plays a Role in NRF1 Transcriptional Regulation. J Biol Chem. 2009; 284:86218632. doi: 10.1074/jbc.M807198200.

16. Jung F, Haendele J, Hoffmann J, Reissner A, Dernbach E, Zeiher AM, Dimmeler S. Hypoxic induction of the hypoxiainducible factor is mediated via the adaptor protein She in endothelial cells. Circ Res. 2002; 91:38-45. doi: 10.1161/01. RES.0000024412.24491.CA.

17. McTigue DM, Tripathi RB. The life, death, and replacement of oligodendrocytes in the adult CNS. J Neurochem. 2008; 107:1-19. doi: 10.1111/j.1471-4159.2008.05570.x.

18. Miller KA, Harkin CP, Bailey PL. Postoperative tracheal extubation. Anesth Analg. 1995; 80:149-172. doi: 10.1097/00000539-199501000-00025.

19. Gosney JR. The effects of hypobaric hypoxia on the corticotroph population of the adenohypophysis of the male rat. J Pathol. 1984; 142:163-168. doi: 10.1002/ path.1711420303.

20. Raff H, Hong JJ, Oaks MK, Widmaier EP. Adrenocortical responses to $\mathrm{ACTH}$ in neonatal rats: effect of hypoxia from birth on corticosterone, StAR, and PBR. Am J Physiol Regul Integr Comp Physiol. 2003; 284:R78-R85. doi: 10.1152/ ajpregu.00501.2002.

21. Liao W, Gao Y, Cai M, Huang J, Chen J. Effect of hypoxia on secretion of testosterone and expression of its synthesis relative protein and enzymes in rats. Chinese J Aerosp Med. 2007; 17:191-195. doi: 10.3760/cma.j.is sn.1007-6239.2006.03.007.

22. Ruohola JK, Valve EM, Karkkainen MJ, Joukov V, Alitalo K, Harkonen PL. Vascular endothelial growth factors are differentially regulated by steroid hormones and antiestrogens in breast cancer cells. Mol Cell Endocrinol. 1999; 149:29-40. doi: 10.1016/S0303-7207(99)00003-9.

23. Liu. G, Yu F, Dai D, Zhang G, Zhang C, Dai Y. Endoplasmic reticulum stress mediating downregulated StAR and 3-betaHSD and low plasma testosterone caused by hypoxia is attenuated by CPU86017-RS and nifedipine. J Biomed Sci. 2012; 19:4. doi: 10.1186/1423-0127-19-4.

24. Wang D, Zhang J, Lu Y, Luo Q, Zhu L. Nuclear respiratory factor-1 (NRF1) regulated hypoxia-inducible factor-1alpha (HIF-1alpha) under hypoxia in HEK293T. IUBMB Life. 2016; 68:748-755. doi: 10.1002/iub.1537.

25. Hwang G-S, Wang S-W, Tseng W-M, Yu C-H, Wang PS. Effect of hypoxia on the release of vascular endothelial growth factor and testosterone in mouse TM3 Leydig cells. Am J Physiol Endocrinol Metab. 2007; 292:E1763-E1769. doi: 10.1152/ajpendo.00611.2006.

26. Minet E, Arnould T, Michel G, Roland I, Mottet D, Raes M, Remacle J, Michiels C. ERK activation upon hypoxia: involvement in HIF-1 activation. FEBS Lett. 2000; 468: 53-58. doi: 10.1016/S0014-5793(00)01181-9.

27. Anand-Ivell R, Heng K, Hafen B, Setchell B, Ivell R. Dynamics of INSL3 peptide expression in the rodent testis. Biol Reprod. 2009; 81:480-487. doi: 10.1095/ biolreprod.109.077552.

28. Anand-Ivell R, Wohlgemuth J, Haren M, Hope PJ, Hatzinikolas G, Wittert GA, Ivell R. Peripheral INSL3 concentrations decline with age in a large population of Australian men. Int J Androl. 2006; 29:618-626. doi: 10.1111/j.1365-2605.2006.00714.x.

29. Martin LJ, Tremblay JJ. The human 3beta-hydroxysteroid dehydrogenase/Delta5-Delta4 isomerase type 2 promoter is a novel target for the immediate early orphan nuclear receptor Nur77 in steroidogenic cells. Endocrinology. 2005; 146: 861-869. doi: 10.1210/en.2004-0859.

30. Su Y, Carey LC, Rose JC, Pulgar VM. Leptin alters adrenal responsiveness by decreasing expression of ACTH-R, StAR, and P450c21 in hypoxemic fetal sheep. Reprod Sci. 2012; 19:1075-1084. doi: 10.1177/1933719112442246.

31. Zhang G-L, Dai D-Z, Zhang C, Dai Y. Apocynin and raisanberine alleviate intermittent hypoxia induced abnormal StAR and 3beta-HSD and low testosterone by suppressing endoplasmic reticulum stress and activated p66Shc in rat testes. Reprod Toxicol. 2013; 36:60-70. doi: 10.1016/j. reprotox.2012.12.002.

32. Kowalewski MP, Gram A, Boos A. The role of hypoxia and HIFlalpha in the regulation of StAR-mediated steroidogenesis in granulosa cells. Mol Cell Endocrinol. 2015; 401:35-44. doi: 10.1016/j.mce.2014.11.023.

33. Sivakumar R, Sivaraman PB, Mohan-Babu N, JainulAbideen IM, Kalliyappan P, Balasubramanian K. Radiation exposure impairs luteinizing hormone signal transduction and steroidogenesis in cultured human Leydig cells. Toxicol Sci. 2006; 91:550-556. doi: 10.1093/toxsci/kfj178.

34. Soleck D, Bernhard G, Lipp M, Wimmer E. Identification of a nuclear respiratory factor-1 binding site within the core promoter of the human polio virus receptor/CD155 gene. J Biol Chem. 2000; 275:12453-12462. doi: 10.1074/ jbc.275.17.12453. 